\title{
Potential pathways of indole acetic acid (IAA) biosynthesis in Euphorbia abyssinica
}

\section{Raf Aerts • Els Prinsen • Bart Muys}

Desert candle (Euphorbia abyssinica J.F. Gmel.) (further referred to as EAG) is a succulent tree of dry deciduous and evergreen montane forest, woodland and shrub savanna. It occurs widely throughout dryland Africa, where it is appreciated as a live fence because it is easily propagated from untreated mature branch cuttings.

In Negussie et al. (2008) we argue that the ability of large EAG branches to regenerate with ease in dry soil may be related to the natural plant growth regulator hormone indole acetic acid (IAA) contained in the latex of the plant.

EAG latex samples from northern Ethiopia $(n=3)$ that were chemically analyzed contained on average $( \pm$ s.e. of mean) $350 \pm 117 \mathrm{pmol}$ IAA /g latex (350 $\mathrm{pmol} / \mathrm{g}=0.06 \mu \mathrm{g} / \mathrm{g}=0.06 \mathrm{mg} / \mathrm{l}$ latex $)$, as well as the IAA metabolites indole lactate (ILA: $477 \pm 12 \mathrm{pmol} / \mathrm{g}$ latex) and indole ethanol (IEt: $316 \pm 73 \mathrm{pmol} / \mathrm{g}$ latex). One sample also contained IAA conjugated to amino-acids (108 pmol/g latex) and glucose (371 pmol/g latex). Here we present a schematic overview of the potential pathways of IAA biosynthesis in EAG (Fig. 1).

The IAA metabolites found in the EAG latex, ILA and IEt, can be converted to indole-3-pyruvic acid (IPA) and indole acetaldehyde (IAAld) respectively. These molecules suggest that auxin biosynthesis in EAG is tryptophane (Trp) dependent. Woodward and Bartel (2005) found similar pathways in the model plant Arabidopsis thaliana Schur where de novo IAA biosynthesis initiates from Trp or Trp precursors.

R. Aerts $(\bowtie) \cdot$ B. Muys

Division Forest, Nature and Landscape, Katholieke Universiteit Leuven, Celestijnenlaan 200E-2411, BE-3001 Leuven, Belgium e-mail: raf.aerts@ees.kuleuven.be

E. Prinsen

Department of Biology, University of Antwerp, Groenenborgerlaan 171, BE-2020 Antwerpen, Belgium 
IAM

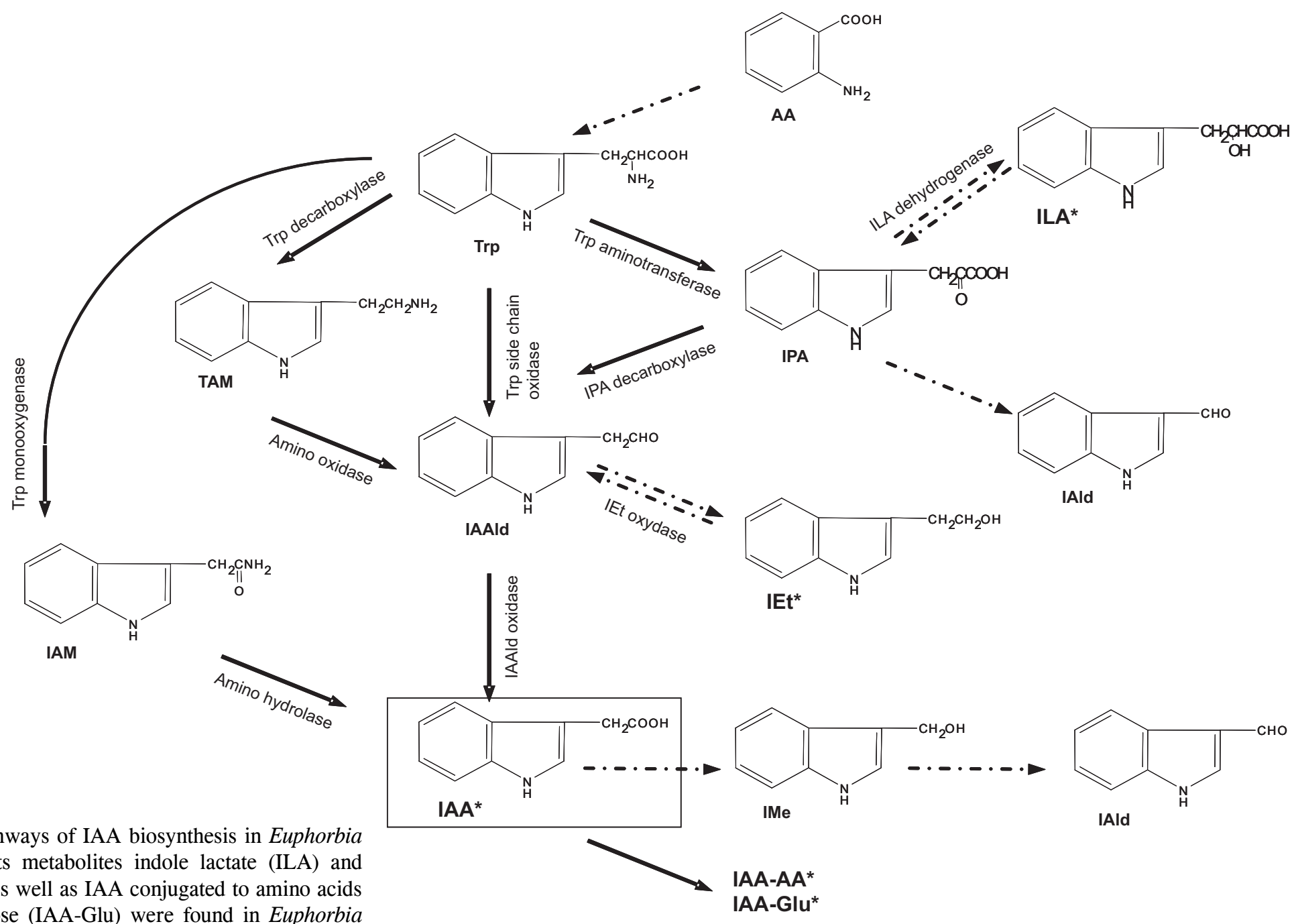
abyssinica. IAA, its metabolites indole lactate (ILA) and indole ethanol (IEt) as well as IAA conjugated to amino acids (IAA-AA) and glucose (IAA-Glu) were found in Euphorbia IAA-GIu* 


\section{References}

Negussie A, Aerts R, Prinsen E, Muys B (2008) Euphorbia abyssinica latex promotes rooting of Boswellia cuttings. New Forests, DOI: 10.1007/s11056-008-9106-7

Woodward AW, Bartel B (2005) Auxin: regulation, action, and interaction. Annals of Botany, DOI: 10.1093/aob/mci083 